\title{
Proceeding
}

Performance Analysis Workshop, 2 - 5 April 2013, Alicante, Spain

\section{Colour contrast and regulation of the long jump approach run}

\author{
APOSTOLOS THEODOROU1 , EMMANOUELA IOAKIMIDOU1', PANAGIOTIS KOURIS', \\ VASSILIOS PANOUTSAKOPOULOS², EMMANOUIL SMPOKOS ${ }^{3}$ \\ ${ }^{1}$ Department of Physical Education and Sports Science, Kapodistrian University of Athens, Greece \\ 2 Biomechanics Laboratory, Department of Physical Education \& Sport Science, Aristotle University of Thessaloniki, \\ Thessaloniki, Greece \\ ${ }^{3}$ Faculty of Physical and Cultural Education, Hellenic Army Academy, Greece
}

\begin{abstract}
Theodorou A, loakimidou E, Kouris P, Panoutsakopoulos V, Smpokos E. Colour contrast and regulation of the long jump approach run. J. Hum. Sport Exerc. Vol. 8, No. Proc3, pp. S681-S687, 2013. Research has shown that visual perception of the take-off board and the subsequent regulation of the approach run occur 4-5 strides prior to take-off. Contrast in visual perception is determined by the difference in colour and occurs when a surface of one colour induces its antagonist colour in an adjoining surface. The aim of the present study was to investigate if colour contrast between the track surface and the board affects the stride regulation pattern at the long jump approach run. Four long jumpers performed long jumps in two different occasions: 6 from a runway track coloured blue, with a white take-off board and 6 from a modified yellow board. The runway was marked and the approach runs were recorded with a panning camera. Toeboard distance (TBD) for each support phase in every run-up and the percentage distribution of adjustment of the regulated strides was calculated. With the white take-off board, the average TBD variability reached its peak value $(21.74 \mathrm{~cm})$ on the 5 th stride from the board and at a distance of $9.77 \mathrm{~m}$ from take-off point. With the yellow take-off board the average TBD variability culminated $(24.80 \mathrm{~cm})$ on the 7 th stride from the board and at a distance of $13.40 \mathrm{~m}$ from take-off point. With the white board, $80 \%$ of the adjustment was distributed during the last two strides as opposed to $61 \%$ with the yellow board. When a take-off board of a colour complementary to the runway's blue track surface is used, athletes initiated their regulation 2 strides earlier. This may be attributed to an enhanced visual perception of the approaching target allowing a more uniform distribution of adjustments during the last two strides of the approach. Key words: PERCEPTION, VISUAL REGULATION, TAKE-OFF BOARD
\end{abstract}

Corresponding author. Department of Physical Education and Sports Science (TEFAA), Kapodistrian University of Athens, 41 EthnikisAntistaseos, 17237 Dafni, Athens, Greece

E-mail: aptheod@phed.uoa.gr

Performance Analysis Workshop, 2 - 5 April 2013, Alicante, Spain

JOURNAL OF HUMAN SPORT \& EXERCISE ISSN 1988-5202

(c) Faculty of Education. University of Alicante

doi:10.4100/jhse.2013.8.Proc3.14

VOLUME 8 | Proc3 | 2013 | S681 


\section{INTRODUCTION}

Perception-action coupling and the notion that locomotion generates information which in turn restrains further motion is a well-established ecological theory. Gibson (1979) claimed, 'We must perceive in order to move, but we must also move in order to perceive' (p.223). Long jump is an event that has been used extensively as a movement model to study target-directed displacement in humans. This is because the approach phase and the technical skill of placing the take-off foot on the board with accuracy, speed and proper mechanics poses significant spatio-temporal demands on the athlete. Research conducted so far (Berg \& Greer, 1995; Bradshow \& Aisbett, 2006; Hay, 1988; Hay \& Koh, 1988; Lee et al., 1982; Scott et al., 1997) suggests that long jumpers, in order to achieve precise foot placement on the board, regulate the final 4-5 strides of the run-up using visual information. Some studies concurred that a time-to-contact optic variable (tau) initiates adjustments in the vertical impulse exerted by the athletes' feet on the track (Lee et al., 1982; Warren et al., 1986) in order to achieve the desired stride length. Most of the studies that followed on the topic stressed the importance of visual information which feeds a continuous control based on a perception-action coupling (Montagne et al., 2000).

In visual perception, contrast is determined by the difference in colour and occurs when a surface of one colour induces its antagonist colour in an adjoining surface (Hurlbert \& Wolf 2004). Goethe (1810) first studied the physiological effect of opposed colors in his "Theory of Colours" in 1810. Hering (1964) proposed the opponent color theory and suggested that the visual system is determined by three antagonistic processes (opposite colours: bright-dark, red-green, yellow-blue). In Hering's opponent-colors diagram, contrasting colors appear in different segments of the color wheel. The further apart from one another in hue the more contrast (Stockam \& Brainard 2009). A prerequisite of perception by the human eye is the ability to assess visual contrast between adjacent surfaces and calculate distances (Dalke et al., 2010). Undoubtedly, a competitor must achieve an early attainment of the spatio-temporal characteristics of his acting environment so that his musculoskeletal system is successfully coordinated in time. This is mainly accomplished by visually processed information (Fitch \& Turvey 1978; Lee, 1980; Turvey 1990). The aim of the present study was to test the hypothesis that colour contrast between the track surface and the board will affect the stride regulation pattern at the long jump approach run.

\section{METHODS}

\section{Participants}

One male $($ age $=21 \mathrm{yr}$., body mass $=67 \mathrm{~kg}$, height $=1.76 \mathrm{~m}$, personal best $=6.85 \mathrm{~m})$ and three females (age $=20 \pm 1$ yr., body mass $=55.5 \pm 7.3 \mathrm{~kg}$, height $=1.67 \mathrm{~m} \pm 0.06$, personal best $=5.50 \pm 0.14 \mathrm{~m}$ ) medium level long jumpers were examined. The study was approved by the University ethics committee. Informed consent was obtained by the participants.

\section{Procedure}

All participants prior participating to the study were examined for normal vision and colour blindness. Measurements took place at an indoor track and field stadium with artificial lighting and controlled luminance conditions. As a reference chart for classifying the colour of the track's surface the National Colour System (NCS) chart was used (Hard \& Sivik, 1981). The Natural Colour System (NCS) is a proprietary perceptual colour model published by the Scandinavian Colour Institute based on the colour opponency description of colour vision proposed by Herring (1964). A fan deck containing all NCS 1950 original colours was placed on the track. The colour of the track matched code S4030-R90B (namely "blue") of NCS chart index while the standard take-off board matched code S0300-N (namely "white"). 
Based on the colour wheel, code S 1075-G90Y (namely "yellow") was picked as the opponent contrasting colour to the track's surface and was used to dye the modified "yellow" take-off board.

One-meter zones were marked on the runway to allow the measurement of the horizontal distance between the athletes' toe and the proximal to the pit edge of the take-off board, named as toe-board distance (Bradshow \& Aisbett, 2006; Berg and Greer, 1995; Hay, 1988; Hay \& Koh 1988; Lee et al., 1982; Scott et al., 1997). The set-up procedure took into account the instructions for the effectiveness of panning techniques for recording (Gervais et al., 1989). All the approach runs were recorded with a digital camera (CASIO EX-F1) operating at a sampling frequency of 300 frames/sec. The camera, positioned $15 \mathrm{~m}$ from the midline of the run-up lane and elevated $4 \mathrm{~m}$ from ground level, was zoomed in on the athletes' feet and was manually panned to allow the subject's entire run-up to be recorded. The data collection set up is illustrated in Figure 1. All the participating athletes performed on two different occasions and in a random order 6 long jump attempts from a "white" take-off board and 6 from a "yellow" take-off board. Only the legal trials were used for the analysis. Each athlete performed at least 5 legal jumps. In total, 47 legal run-ups were included in the analysis.

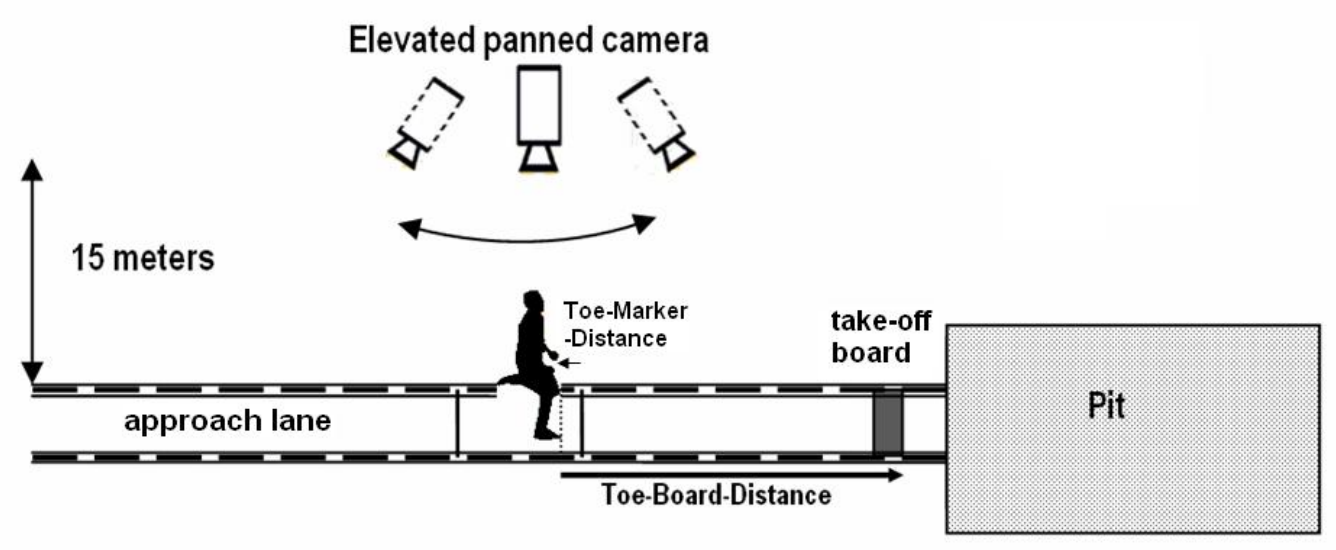

Figure 1. Set up of the experimental procedure

The frames of each foot contact on the ground were extracted from the digital video recordings and transferred for analysis using the APAS 2010 software (Ariel Dynamics Inc., Trabuco Canyon, CA). To calculate the toe-board distances (TBD) for each support phase in every run-up of an athlete, the model described by Chow (1987) and adapted by Hay and Koh (1988) was used. One-meter zones were marked on the runway to allow the measurement of the horizontal distance between the athletes' toe and the proximal to the pit edge of the take-off board (toe-board distance, TBD). At first, the toe-marker distance was designated by projecting the position of the athlete's shoe toe onto a line between the two near markers. TBD was then calculated by the addition of the toe-marker distance and the marker-board distance (Figure 1).

The validity of the procedure for calculating the TBD was assessed by recording a panning video with shoes placed on the runway at known distances $(0.10 \mathrm{~m}, 1.0 \mathrm{~m}, 2.0 \mathrm{~m}$ and thereon in two meter intervals from $3.0 \mathrm{~m}$ up to $25.0 \mathrm{~m}$ from the front edge of the take-off board). The TBD of the calibration shoe was then calculated with the method described above. The comparison between the actual shoe-toe distance and the distance extracted from the video analysis presented a variability of $0-1 \%$. 


\section{Measures}

The standard deviation (SD) of the TBD for each contact of an athlete's foot on the ground across all his trials was calculated. This reflected the variability in foot placement for a particular stride (Berg et al., 1994; Hay \& Koh, 1988; Lee et al., 1982). The length of a stride was defined as the horizontal distance from the toe of one foot to that of the other between two consecutive support phases on the ground and it was determined by the subtraction of the respective TBD (Berg \& Greer, 1995). The regulation of strides was considered to begin at the point (support phase of foot on the ground) at which the maximum value of SD in TBD (TBD SDmax $_{\text {m }}$ was recorded (indicating the termination of an ascending trend of variability), provided that the successive values of SD decreased systematically thereafter (Berg et al., 1994). The distance of the point at which regulation commenced from the board was measured in meters. The SD of TBD recorded at the last stride $\left(\mathrm{TBD}_{\mathrm{SDt}}\right)$ reflected the proximity of the take-off foot placement on the board and therefore the accuracy in targeting the board.

The percentage distribution of adjustment (ADJ\%) in each one of the regulated strides was calculated for each participant following the method suggested by Hay (1988) where $i$ is the ith-last contact:

$$
A D J_{\%}=\frac{\left(T B D_{S D i}-T B D_{S D i-1}\right)}{\left(T B D_{S D \max }-T B D_{S D t o}\right)} \times 100
$$

\section{RESULTS}

In regards to TBD, with the "white" take-off board, participants demonstrated a progressively increased mean SD of TBD that reached a TBD sDmax of $0.24 \mathrm{~m}$ on the 6th support phase (i.e. 5th stride from the board) at a mean distance of $9.97 \mathrm{~m}$ from take-off point. With the "yellow" take-off board they reached a TBD sDmax of $0.25 \mathrm{~m}$ on the 8 th support phase (i.e 7 th stride from the board) at a mean distance of $13.40 \mathrm{~m}$ from take-off point (Figure 2). The ADJ\% made in both conditions is presented in Figure 3.

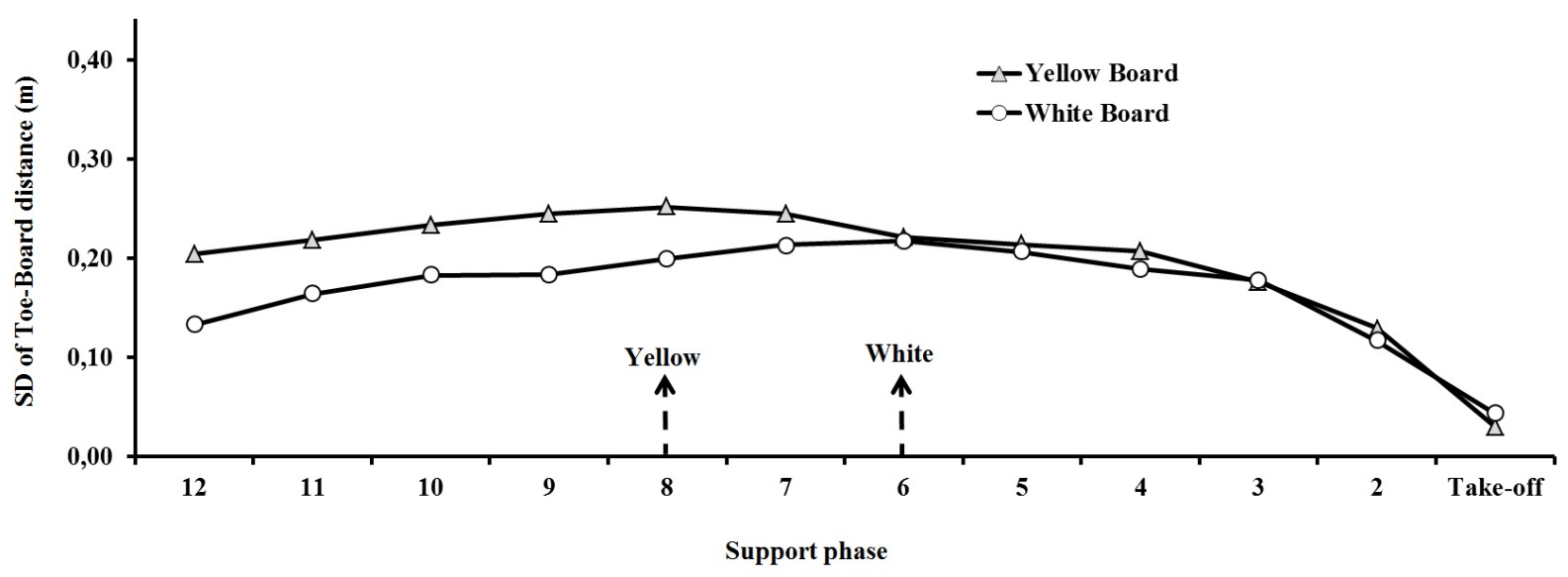

Figure 2. Trend of SD of toe-board distance and onset of regulation with the yellow and white take-off board. Arrows indicate the stride on which stride regulation commenced 


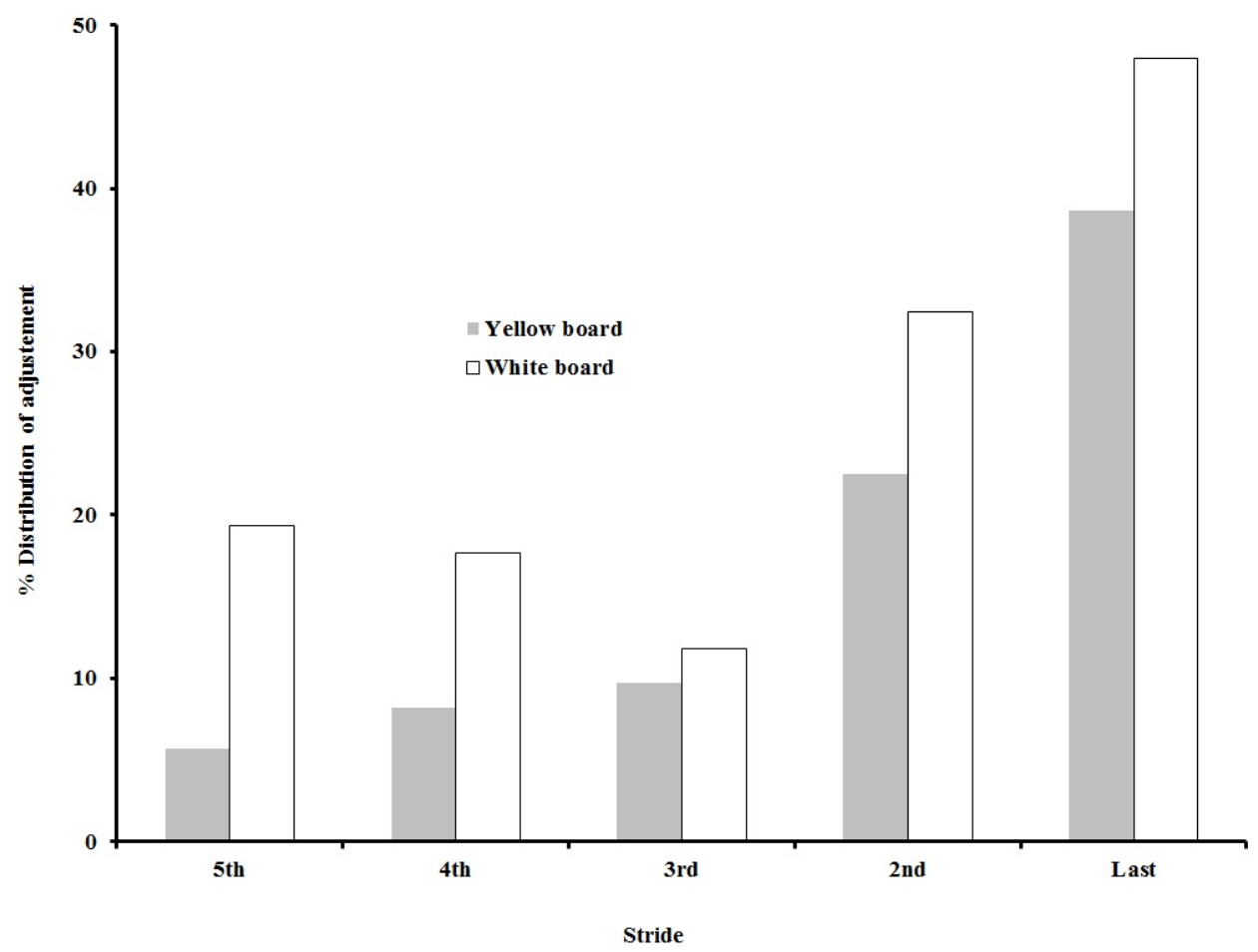

Figure 3. Percentage distribution of the adjustment made in the two conditions

\section{DISCUSSION AND CONCLUSIONS}

\section{Discussion}

The objective of the current study was to establish if the pattern of footfall variability of medium level long jumpers during the approach phase of the long jump is affected by the colour of the take-off board. Previous findings (Berg \&Greer, 1995; Bradshow \& Aisbett, 2006; Hay, 1988; Hay \& Koh, 1988; Galloway \& Connor, 1999; Scott et al., 1997) suggest that the athletes, regardless of their proficiency, exhibit an ascending-descending trend of variability in foot placement over trials. The maximum SD of TBD is considered to be a measure of this variability and the consistency of the approach run. The values of TBD SDmax recorded at the present study (both with the white or the yellow take-off board) were similar to those reported in elite athletes $(0.22 \mathrm{~m}$ to $0.27 \mathrm{~m}$ in Hay, 1988; Hay and Koh, 1988). However, the starting point of the descending pattern of variability, which signals the commencement of the regulatory mechanism, was comparable to that reported in the literature for the white board only. When the yellow board was in use, participants attained their TBD SDmax $_{\text {mo }}$ two strides earlier. It is believed (Berg et al., 1994; Glize \& Laurent, 1997; Hay \& Koh, 1988; Lee et al., 1982) that the sudden decrease in SD of TBD distance reflects the replacement of the stereotyped gait pattern with one that is based on jumpers' perception of the take-off board.

Our data suggest that athletes attempting from a take-off board of a contrasting colour with the tracks' surface perceived the approaching target earlier and commenced corrective adjustments of their approach run promptly. As shown in Figure 3, this resulted to a more uniform distribution of the adjustments made across the last 5 strides when the "yellow" take-off board was used. With the "white" take-off board, $80 \%$ of the corrections were distributed over the last two strides of the approach run. These findings are similar to 
those reported for elite athletes (Hay, 1988), novice athletes (Berg et al., 1994) and unskilled athletes (Scott et al., (1997), where the majority of the adjustments also took place on the last two strides of the approach. According to Hay (1988), it seems odd that elite athletes perform the major adjustments in their stride lengths during the preparation for take-off which is the most inopportune time for such an action. Berg et al., (1994), who noticed the same pattern in novice athletes, suggested that the regulation of gait must be analysed in terms of the interaction between a jumper and his/her environment and the coupling of perception and action in human bipedal motion. The observation that only $61 \%$ of the adjustments were distributed over the last two strides when the "yellow" take-off board was used supports this notion. Early perception of the take-off board and time to contact would allow athletes to distribute the corrections needed uniformly across the last segment of the approach. This would allow them during the last two strides to focus without distraction on high speed attainment and proper take-off mechanics during the last two strides.

The issue of colour contrast in the long jump and triple jump setting has also been raised by Linthorne (2005). The author examined the possible effect that colour contrast among the take-off board and the adjoining plasticine indicator could have in the likelihood of a foul. The author reported that in competitions where the plasticine indicators in use had "white" as the prevailing colour, more foul attempts were recorded and suggested that the IAAF should standardize the colour of the plasticine indicator board and the plasticine. In the last years there is an on growing tendency modern athletics amenities to use various colour hues for the track's surface. However, since IAAF's specifications for track and field facilities require the take-off board to be coloured exclusively "white" this would result to variable levels of colour contrast. Undoubtely, further research is needed examining the effect of colour contrast on the perception of the board with surfaces of different hues (red, green) taking also into account the effect of luminance contrast as well with the use of a spectroradiometer.

\section{Conclusion}

When a take-off board of a colour complementary to the runway's blue track surface is used athletes initiated their regulation two strides earlier. This may be attributed to an enhanced visual perception of the approaching target. This resulted in a more uniform distribution of adjustments during the last two strides of the approach, allowing the athlete to focus on high speed attainment and proper take-off mechanics.

\section{REFERENCES}

1. BERG WP, WADE MG, GREER NL. Visual Regulation of Gait in Bipedal Locomotion: Revisiting Lee, Lishman, and Thomson (1982). J. Exp. Psychol. Human. 1994;20 (4): 854-863

2. BERG WP, \& GREER NL. A kinematic profile of the approach run of novice long jumpers. J. Appl. Biomech. 1995; 11: 142-162.

3. BRADSHAW EJ, AISBETT B. Visual Guidance during Competition Performance and Run-through Training in Long Jumping. Sport. Biomech. 2006; 5(1): 1-14.

4. CHOW JW. (1987). Maximum speed of female high school runners. Int. J. Sport Biomech., 3(2), 110-127.

5. DALKE H, CONDUIT GJ, CONDUIT BD, COOPER R, CORSO A, WYATT D. Colour contrast assessment system: design for people with visual impairment. In P. Langdon P. J. Clarkson and P. Robinson (Eds.), Designing Inclusive Interactions. Springer. 2010.

6. FITCH H, TURVEY MT. On the control of activity: Some remarks from an ecological point of vie. In D.Landers \& R.Christina (Eds.) Psychology of Motor Behavior and Sport. Champaign IL: Human Kinetics. 1978 
7. GALLOWAY M, CONNOR K. (1999). The effect of steering on stride pattern and velocity in long jump. In R.H. Sanders and B.J. Gibson (eds.), Scientific Proceedings of the XVII International Symposium on Biomechanics in Sports (pp.41-44). Perth: Edith Cowan University. 1999

8. GERVAIS P, BEDINGFIELD EW, WRONKO C, KOLLIAS I, MARCHIORI G, KUNTZ J, WAY N, KUIPER D. Kinematic measurement from panned cinematography. Can. J. Sport Sci. 1989; 14: 107-111.

9. GIBSON JJ. An ecological Approach to visual perception. Boston MA: Houghton-Mifflin. 1979

10. GLIZE D, LAURENT M. Controlling locomotion during the acceleration phase in sprinting and long jumping. J. Sport. Sci., 1997. 1997; 15: 181-189.

11. GOETHE JW. VON. (1810). Farbenlehre. Reproduced from the 1840 translation by C.L. Eastlake, Theory of colours. Cambridge, Massachusetts: The MIT Press. 2000.

12. HARD A, SIVIK L. NCS-Natural Color System: A Swedish Standard for Color Notation. Color Res. Appl., 6, 129-138. 1981

13. HAY JG. Approach strategies in the long jump. Int. J. Sport Biomech. 1988; 4: 114-129.

14. HAY JG, KOH TJ. Evaluating the approach in horizontal jumps. Int. J. Sport Biomech. 1988; 4: 372-392.

15. HERING E. Outlines of a Theory of the Light Sense. Cambridge: Harvard University. 1878/1964.

16. HURLBERT A. WOLF K. Color contrast: a contributory mechanism to color constancy. Prog. Brain Res. 2004; 144: 147-160.

17. LEE DN. Visuo-motor coordination in space-time. In G.E. Stelmach \& J. Requin (Eds.). Tutorials in Motor Behavior. Amsterdam: Elsevier Science. 1980

18. LEE DN, LISHMAN JR, THOMSON JA. Regulation of gait in long jumping. J. Exp. Psychol. Human. 1982; 8: 448-459.

19. LINTHORNE NP. The color of the plasticine indicator board in the horizontal jumps. Track Coach. 2005; 171: 5466-5468.

20. MONTAGNE G, CORNUS S, GLIZE D, QUAINE F, LAURENT M. A perception-action coupling type of control in long jumping. J. Motor Behav. 2000; 32: 37-43.

21. SCOTT MA, LI F, DAVIDS K. Expertise and the regulation of gait in the approach phase of the long jump. J. Sport. Sci. 1997; 15: 597-605.

22. STOCKMAN A, BRAINARD DH. Color vision mechanisms. In M. Bass, C. DeCusatis, J. Enoch, V. Lakshminarayanan, G. Li, C. Macdonald, V. Mahajan \& E. van Stryland (Eds.), The Optical Society of America Handbook of Optics, 3rd edition, Volume III: Vision and Vision Optics. NewYork: McGrawHill. 2009.

23. TURVEY MT. Coordination. Am. Psychol. 1990; 45: 938-953.

24. WARREN WH, YOUNG DS, LEE DN. Visual control of step length during running over irregular terrain. J. Exp. Psychol. Human. 1986; 12(3): 259-266. 